\title{
Clival canal Angle and Basal Angle in Nepalese Population- A Computed Tomography Based Study
}

\author{
Jagat Narayan Rajbanshi, ${ }^{1}$ Archana Chaudhary, ${ }^{2}$ Pankaj Raj Nepal, ${ }^{1}$ Dinesh Kumar Thapa, ${ }^{1}$ Navin \\ Kumar Yadav. ${ }^{1}$
}

${ }^{1}$ Department of Neurosurgery, B and C Medical College Teaching Hospital and Research Center, Birtamode, Jhapa, Nepal

${ }^{2}$ Department of Forensic Medicine, B and C Medical College Teaching Hospital and Research Center, Birtamode, Jhapa, Nepal.

Correspondence:

Dr. Jagat Narayan Rajbanshi

Department of neurosurgery

B and C Medical College Teaching Hospital and Research Center, Birtamode, Jhapa, Nepal

Email: sergiorajbanshi@gmail.com

Phone: +9779818101187

\begin{abstract}
Background: Clival canal angle is an angle formed by the clivus and the posterior longitudinal ligament of the cervical spine and Welcher basal angle formed between the line joining the nasion to tuberculumSella and the line joining the tuberculum sellae to basion along the plane of clivus. With the aim to review the normal distribution of clival canal angle and basal angle in the Nepalese population this study was performed. Methods and materials: This is a cross-sectional analytical study with non- probability consecutive sampling technique done over the duration of 3 months. A reconstructed image of a bone window in the midsagittal plane was selected and measurement of the angles was done in CT console. Results: There was a total of 60 patients in this study with male predominance (figure 3). The mean age of the population was 49.8 (SD 18.8) years. The clival canal angle reference range was 130.8 to 168.8 degrees with a mean 149.8(SD 9.5) degree. Similarly, the reference range of Welcher basal angle in the study population was 115.49 to 140.29 degree with a mean of 127.89 (SD: 6.4) degrees. Conclusion: The mean clival canal angle in the Nepalese population is 149.8 (SD:9.5) degrees and the mean basal angle is 127.89 (SD: 6.4) degree.
\end{abstract}

Key words: Basal angle, Basilar invagination, Clival canal angle, Craniovertebral Junction.

$\sim$

lival canal angle is an angle formed by the clivus and the posterior longitudinal ligament of the cervical spine. It is around 132.3 to 173 degrees in the normal population. $^{1,2}$ The Welcher basal angle is formed between the line joining the nasion to tuberculumSella and the line joining the tuberculum sellae to basion along the plane of clivus. ${ }^{3}$ These angles are commonly used during the evaluation of pathologies around craniovertebral junction (CVJ). ${ }^{4,5}$ With the aim to review the normal distribution of clival canal angle and basal angle in the Nepalese population, this study was performed

\section{Methods and Materials:}

Types of study: a cross-sectional analytical study

sampling technique: Non- probability of consecutive sampling

Duration of study: 3 months 
Site of study: B and C Medical College Teaching Hospital and Research Center, Birtamode, Jhapa, Nepal

Inclusion criteria: CT-scan of all age group and gender done for various region

Exclusion criteria: CT-scan of the head where there is local destruction of the anterior cranial fossa, clivus, or cervical spine

Data Collection and Analysis: All the patients whose CT-scan of the head was done during the period of data collection were enrolled in the study. A reconstructed image of the bone window in the midsagittal plane was selected, and measurement of the angles was done in CT console as shown in figure1 and figure 2.

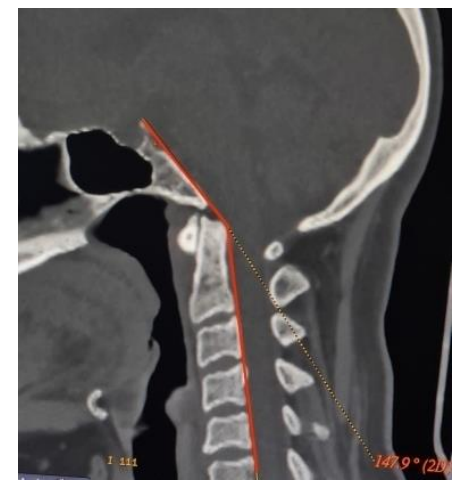

Figure 1: Clivocanal angle measurement

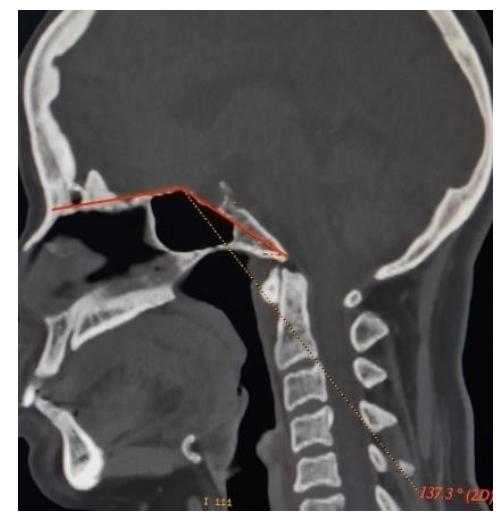

Figure 2: Basal angle measurement

Age, clivalcanal angle, and Welcher basal angle were presented as mean and standard deviation (SD). Gender was presented as frequency and percentage. The normal distribution curve of the clival canal angle and basal angle were obtained using SPSS20. Finally, the correlation was done to evaluate the association of age and gender with the clival canal and basal angle.

\section{Results:}

There was a total of 60 patients enrolled in this study with male predominance (Figure 3).

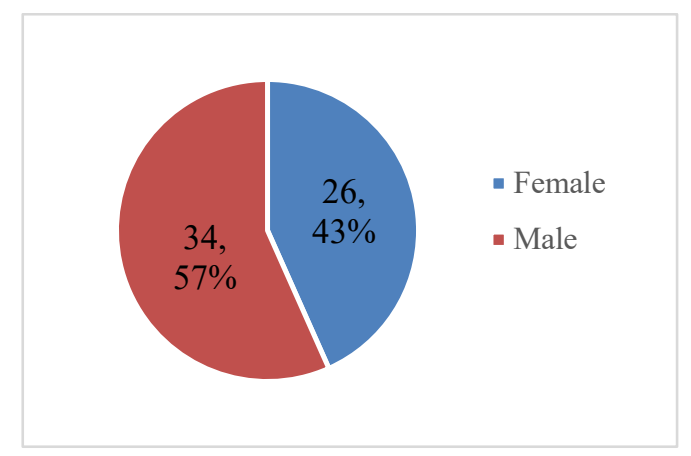

Figure 3: Gender distribution of the study sample

The mean age of the population was 49.8 (SD 18.8) years. The clival canal angle ranged between 126.6 to 171.1 degree with a mean of 149.8 (SD 9.5) degree (Table 1).

Table 1: Descriptive parameter of various variables

\begin{tabular}{lcccc}
\hline & Minimum & Maximum & Mean & Std. Deviation \\
& & & & \\
\hline Age & 17 & 90 & 49.8333 & 18.8231 \\
Clival canal & & & & \\
angle & 126.6 & 171.1 & 149.807 & 9.51233 \\
Basal angle & 108.1 & 140.2 & 127.89 & 6.39888 \\
& & & & \\
\hline
\end{tabular}

The clival canal angle was normally distributed as shown in figure 2 so the reference range of the clival canal angle in the Nepalese population was 130.8 to 168.8 degree (mean+/- 2SD). 


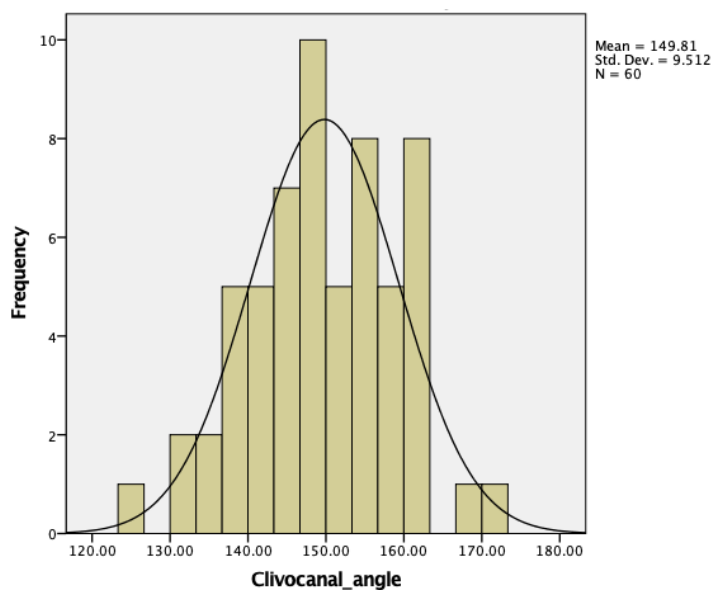

Figure 4: Normal distribution of the Clival canal angle

Similarly, the range of Welcher basal angle in this study was 108.1 to 140.2 degree with a mean of 127.89(SD: 6.4) (Table 1). The Welcher basal angle was also normally distributed in the study of this population as shown in figure 5 .

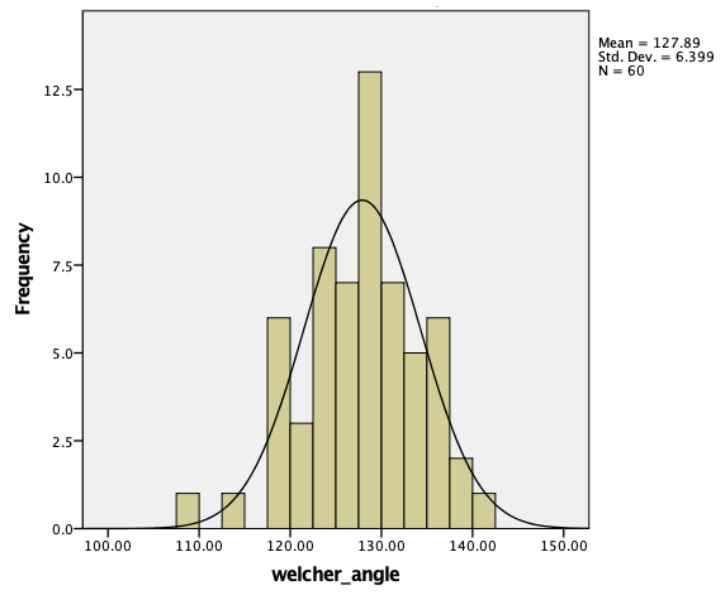

Figure 5: Normal distribution of the basal angle

The reference range for this population was 115.49 to 140.29 degree (Mean +/- 2SD).

The correlation of age with clivalcanal angle and welcher angle did not show any statistical significance. Similarly, the comparison of means of angles measured between males and females was also statistically not significant.

\section{Discussion:}

Platybasia has been linked with basilar invagination and various other forms of neurological deterioration. ${ }^{6,7}$ Two most common angles used for the diagnosis of platybasia are the basal angle and clival canal angle. Normally, a basal angle $>143$ degrees with a clival canal $<150$ degrees has been considered as a reference value for diagnosing platybasia. ${ }^{3,8}$ The normal value of basal angle seems to range between 100 to 128 degree in difference literature. ${ }^{8,9}$

The reference range of basal angle seems to vary with geographical variation and also the technique of measurement. In the Nepalese population, our study showed a mean of 127.89 degrees (SD 6.4), which seems to be within the range of previous studies of Filipino, Indian, Brazilian, North American, and Turkish populations. ${ }^{8,9,10}$ Among them the reference range of our study seems to be very close to the study performed in the Indian population. This might be due to open border policy between Nepalese and Indian territory, cultural similarity, and similar body structure of south Asian territory.

Clival canal angle is an important parameter commonly used during the evaluation of basilar invagination, chairi malformation, platybasia, rheumatoid arthritis involving the odontoid, and so on. ${ }^{5}$ This angle when decreases below 135 to 145 degree further cause neurological deterioration secondary to brain stem compression by the odontoid process. The reference normal range of clival canal angle in the normal population is from 132.3 to 173 degrees with a mean of around 153.6 degrees in different studies. ${ }^{2,11}$ In our study of the Nepalese population, the mean clival canal angle was 149.8 degrees, which seems to be similar to the reference range of previous studies.

The association of clival canal angle and basal angle with the age, and gender were not statistically significant in our study. This result was also consistent with the previous studies. ${ }^{12}$

\section{Conclusion:}

The mean clival canal angle in the Nepalese population is 149.8 (SD:9.5) degree and the mean basal angle is 127.89 (SD: 6.4) degree.

\section{References:}


1. Martin JE, Bookland M, Moote D, Cebulla C. Standardized method for the measurement of Grabb's line and clival-canal angle. Journal of Neurosurgery: Pediatrics. 2017 Oct 1;20(4):352-6.

2. Botelho RV, Ferreira ED. Angular craniometry in craniocervical junction malformation. Neurosurgical review. 2013 Oct 1;36(4):603-10.

3. Ferreira JA, Botelho RV. The odontoid process invagination in normal subjects, Chiari malformation and Basilar invagination patients: pathophysiologic correlations with angular craniometry. Surgical Neurology International. 2015;6.

4. Gupta PP, Dhok AM, Shaikh ST, Patil AS, Gupta D, Jagdhane NN. Computed tomography evaluation of craniovertebral junction in asymptomatic central rural Indian population. Journal of Neurosciences in Rural Practice. 2020 Jul;11(3):442.

5. Goel A. Basilar invagination, Chiari malformation, syringomyelia: a review. Neurology India. 2009 May 1;57(3):235.

6. Gustafson WA, Oldberg E. Neurologic significance of platybasia. Archives of Neurology \& Psychiatry. 1940 Dec 1;44(6):1184-98.

7. COGAN DG, BARROWS LJ. Platybasia and the ArnoldChiari malformation. AMA archives of ophthalmology. 1954 Jul 1;52(1):13-29.

8. Koenigsberg RA, Vakil N, Hong TA, Htaik T, Faerber E, Maiorano T, Dua M, Faro S, Gonzales C. Evaluation of platybasia with MR imaging. American journal of neuroradiology. 2005 Jan 1;26(1):89-92.

9. Botelho RV, Ferreira JA, Ferreira ED. Basilar invagination: A craniocervical kyphosis. World neurosurgery. 2018 Sep 1;117: e180-6.

10. Dash C, Singla R, Agarwal M, Kumar A, Kumar H, Mishra S, Sharma BS. Craniovertebral junction evaluation by computed tomography in asymptomatic individuals in the Indian population. Neurology India. 2018 Jan 5;66(3):797.

11. Batista UC, Joaquim AF, Fernandes YB, Mathias RN, Ghizoni E, Tedeschi H. Computed tomography evaluation of the normal craniocervical junction craniometry in 100 asymptomatic patients. Neurosurgical Focus. 2015 Apr 1;38(4): E5.

12. Besachio DA, Khaleel Z, Shah LM. Odontoid process inclination in normal adults and in an adult population with Chiari malformation Type I. Journal of Neurosurgery: Spine. 2015 Dec 1;23(6):701-6. 